\title{
A patient with intraoperative awareness history requiring high propofol effect-site concentrations for general anesthesia
}

\author{
Shinju Obara ${ }^{*}$ (D), Yoshie Noji ${ }^{2}$, Takayuki Hasegawa ${ }^{2}$, Chie Hanayama ${ }^{2}$, Rieko Oishi ${ }^{2}$ and Masahiro Murakawa ${ }^{3}$
}

To the Editor,

Intraoperative awareness (IA) occurs in up to $0.12 \%$ of patients under general anesthesia [1]. Herein, we describe the case of patient with IA history requiring high propofol effect-site concentrations (PCe) for anesthesia. We obtained a written informed consent from the patient for publication. The patient was a 34-year-old woman $(158 \mathrm{~cm}, 46$ $\mathrm{kg}$ ) who underwent a semi-emergency transcutaneous drainage of an intrapelvic tumor under computed tomography (CT) guidance. She was being administered celecoxib, loxoprofen, and pregabalin for chronic pain. She had undergone multiple operations for neurilemmomas, had experienced IA with unclear details, and desired a complete loss of consciousness for her upcoming operation. In the CT room, we induced anesthesia with fentanyl $(150 \mu \mathrm{g})$ and propofol via target-controlled infusion (TCI, Diprifusor model, TE-371, Terumo, Tokyo, Japan). We initiated the target plasma concentration of propofol at $4 \mu \mathrm{g} / \mathrm{mL}$ and increased it gradually (Fig. 1). When the patient's responses to voice, mild prodding, and shaking were lost, the PCe was $6.4 \mu \mathrm{g} / \mathrm{mL}$ and the patient state index (PSi) derived with SedLine $^{\bullet}$ (Masimo, USA) was 79 (PSi 25-50 is recommended during anesthesia). At this stage, fast waves in electroencephalogram were still observed but were not predominant. Spectral edge frequency (SEF), which can be used as a surrogate measure to observe the change in the amount of fast waves, was $12.9 \mathrm{~Hz}$. Following the tracheal intubation using rocuronium $(40 \mathrm{mg})$, we moved the patient to a prone position and installed a mechanical ventilator. We titrated target propofol concentrations in accordance with PSi values and with the patient's vital signs. The drainage was uneventfully completed. The maximum PCe was $8.0 \mu \mathrm{g} / \mathrm{mL}$ and the total fentanyl dose was $400 \mu \mathrm{g}$. Ten minutes after PCe reached $8.0 \mu \mathrm{g} / \mathrm{mL}$, PSi and SEF were 22 and $10.8 \mathrm{~Hz}$, respectively. The anesthesia duration was $100 \mathrm{~min}$. The patient regained responsiveness to voice when the PCe decreased to $4.0 \mu \mathrm{g} / \mathrm{mL}$. We did not observe any postoperative complications and the patient was satisfied with the clinical course without any IA. Although no consensus exists on IA, using inhalation anesthetics may produce less IA [2, 3]. However, the CT room was not equipped with the excess anesthesia gas extraction system and this prevented us from using inhaled anesthetics with an anesthesia machine, which is why we chose total intravenous anesthesia. Our patient required much higher PCes than usual (TCIs are 3.0$6.0 \mu \mathrm{g} / \mathrm{mL}$ and $2.0-5.0 \mu \mathrm{g} / \mathrm{mL}$ for anesthesia induction and maintenance, respectively; according to the propofol package insert; Diprivan ${ }^{\circ}$, Aspen Japan, Tokyo). The patient was apparently awake, although the probability of loss of response to prodding and shaking right before the patient lost responsiveness was predicted at $99.3 \%$ with the response surface model [4]. Therefore, we think she was relatively insensitive to propofol due to pharmacokinetic and/or pharmacodynamic variability, and this may have explained her previous IA. Although pregabalin reportedly reduces propofol requirements [5], our patient required a large propofol dose. Our case highlights the need to

\footnotetext{
* Correspondence: obashin99@gmail.com

${ }^{1}$ Surgical Operation Department, Fukushima Medical University Hospital, 1

Hikarigaoka, Fukushima, Fukushima 960-1295, Japan

Full list of author information is available at the end of the article
} 


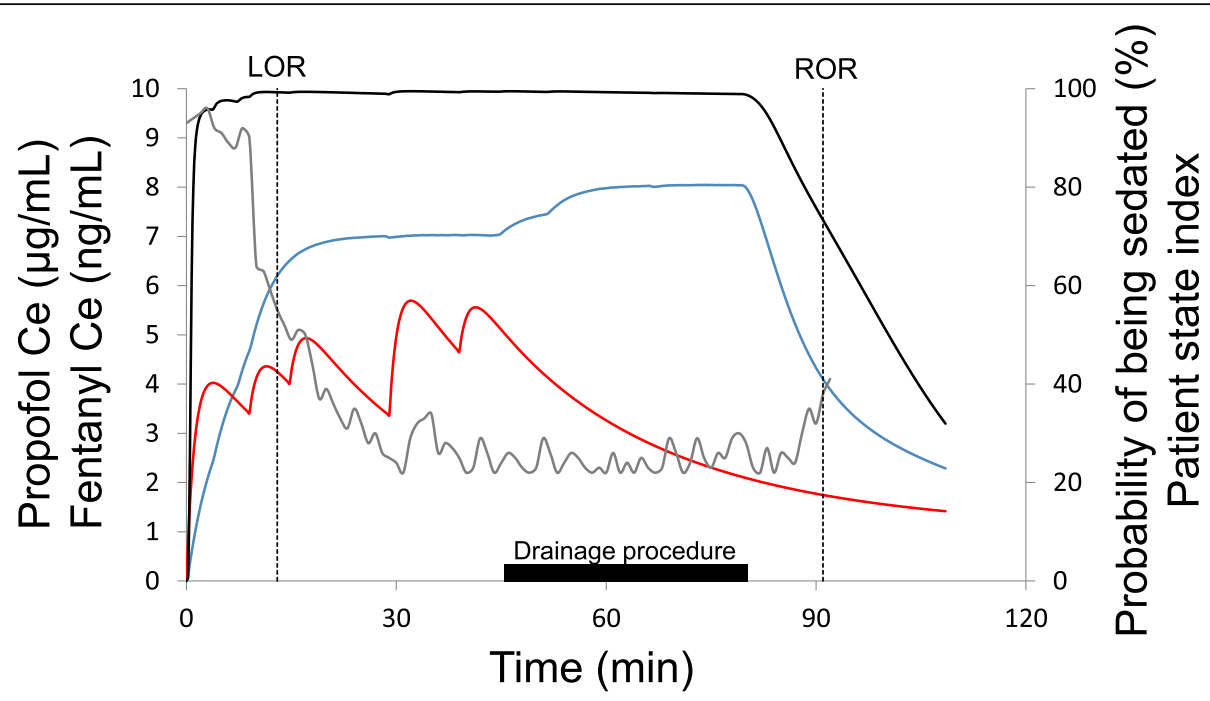

Fig. 1 Time courses of propofol effect-site concentration (PCe, blue curve), fentanyl effect-site concentration (FCe, red curve), patient state index (PSi, gray curve), and probability of loss of response to prodding and shaking predicted with a response surface model (black curve) [4]. To use the model, (1) we converted PCes predicted with Diprifusor model to PCes predicted by Schinder model using the infusion record of propofol downloaded from the pump and (2) converted the FCes to remifentanil equivalents using a remifentanil:fentanyl equivalency ratio of 1:1.2. LOR, loss of responsiveness; ROR, return of responsiveness

be aware of potential propofol insensitivities, especially in patients with IA history.

\section{Abbreviations}

CT: Computed tomography; FCe: Fentanyl effect-site concentration; IA: Intraoperative awareness; PCe: Propofol effect-site concentration; PSi: Patient state index; TCI: Target-controlled infusion

\section{Acknowledgements}

None

\section{Authors' contributions}

SO treated the patient and wrote the manuscript. YN and RO treated the patient and revised the manuscript. $\mathrm{TH}$ treated the patient. $\mathrm{CH}$ and $\mathrm{MM}$ helped to design the case report. All authors reviewed and approved the final draft.

\section{Funding}

The authors declare no funding for this report.

\section{Availability of data and materials}

Not applicable

\section{Ethics approval and consent to participate}

In our institution, IRB approval is not required for a case report.

\section{Consent for publication}

Written informed consent was obtained from the patient for publication of this case report

\section{Competing interests}

The authors declare that they have no competing interests.

\section{Author details}

'Surgical Operation Department, Fukushima Medical University Hospital, 1 Hikarigaoka, Fukushima, Fukushima 960-1295, Japan. ${ }^{2}$ Department of Anesthesiology, Fukushima Medical University Hospital, 1 Hikarigaoka, Fukushima, Fukushima 960-1295, Japan. ${ }^{3}$ Department of Anesthesiology, Fukushima Medical University School of Medicine, 1 Hikarigaoka, Fukushima, Fukushima 960-1295, Japan.
Received: 28 August 2019 Accepted: 4 October 2019

Published online: 04 November 2019

\section{References}

1. Walker EMK, Bell M, Cook TM, Grocott MPW, Moonesinghe SR. Patient reported outcome of adult perioperative anaesthesia in the United Kingdom: a cross-sectional observational study. Br J Anaesth. 2016;117:75866.

2. Morimoto Y, Nogami Y, Harada K, Tsubokawa T, Masui K. Awareness during anesthesia: the results of a questionnaire survey in Japan. J Anesth. 2011;25: 72-7.

3. Domino KB, Posner KL, Caplan RA, Cheney FW. Awareness during anesthesia: a closed claims analysis. Anesthesiology. 1999;90:1053-61.

4. Johnson KB, Syroid ND, Gupta DK, Manyam SC, Egan TD, Huntington J, White $J$ L, Tyler D, Westenskow DR. An evaluation of remifentanil propofol response surfaces for loss of responsiveness, loss of response to surrogates of painful stimuli and laryngoscopy in patients undergoing elective surgery. Anesth Analg. 2008;106:471-9 table of contents.

5. Chavush MA, Yagar S, Erturk A, Ozgok A. Preliminary investigation of preoperative pregabalin and total intravenous anesthesia doses: a randomized controlled trial. J Clin Anesth. 2017:41:137-40.

\section{Publisher's Note}

Springer Nature remains neutral with regard to jurisdictional claims in published maps and institutional affiliations. 